\title{
Treatment of patients who lack capacity
}

\section{Implications of the L. v. Bournewood Community Trust ruling}

\author{
Gill Livingston, Sheila Hollins, Cornelius Katona, Helen Matthews, \\ Angela Hassiotis, Martin Blanchard, Nick Bouras, Kim Davidson, \\ Janet Carrick, Lindsay Gee and Stella Wiltshire
}

The case of L. $v$. Bournewood Community Trust concerned an autistic man without the capacity to consent to admission, who was admitted informally to a learning-disability hospital. The Court of Appeal (and therefore the law at present) held that he was unlawfully detained, and that patients who lack capacity to consent to hospital admission cannot receive treatment for mental disorder as informal patients. The judgement may be overturned following further review in the House of Lords.

The National Health Service (NHS) Executive has informed health authorities, trusts, social services departments, the Mental Health Act Commission and the relevant Royal Colleges that "the judgement has very significant implications for the management of patients who lack the capacity to consent - particularly people with a learning disability and those suffering from dementia". Patients lacking this capacity "cannot be informally admitted to hospital for assessment or treatment of a mental disorder even if they do not dissent" (Brown, 1997). The NHS Executive states that those who lack capacity and fulfil criteria for admission under Section 2 or 3 of the 1983 Mental Health Act (MHA) should be detained, and that this applies to both prospective admissions and current patients.

The NHS Executive defines capacity to consent to admission (or to treatment) as the abilities "to take in and retain the information material to the decision, especially as to likely consequences of having or not having the treatment", and "to weigh the information in the balance as part of a process of arriving at the decision". Such consent must be "voluntary and continuing". Treatment according to the MHA (Section 145) includes nursing care and psychological treatment as well as physical treatments, habilitation and rehabilitation under medical supervision.

Most hospital patients with a learning disability or dementia would fail the test of capacity. as would many patients with psychoses (particularly schizophrenia and delusional depression). Current practice is for consent to be assumed in the absence of dissent. This judgement, therefore, mandates a radical change in practice with implications in terms both of resources and of distress to patients and their families.

In the year to March 1997, 620 learningdisability patients in England and Wales were detained under the MHA (Department of Health figures, further details available from the author upon request). As there are now approximately 8000 in-patients in learning-disability hospitals (many of whom lack the capacity to consent), MHA-related work in assessing capacity to consent and (usually) detaining them would increase 10-fold. There will be a similar increase for patients with dementia (14\% of total psychiatric in-patients; Smith et al, 1995). We estimate that full implementation would result in at least a three-fold increase in the number of detained people with 'mental illness' (9595 in the year to March 1997; Department of Health figures, further details available from the author upon request).

It is impossible to see how the financial, medical, legal and social service resources for this can be identified within current budgets. The initial section assessment requires two medical practitioners (who cannot both work for the same hospital) and a social worker. In addition, all sections must be reviewed regularly by clinicians, independent doctors, the MHA managers and/or mental health review tribunals.

This problem could theoretically be addressed by allocating extra funds to mental health. In contrast, there is no obvious solution to the distress caused to people with a mental illness or mental impairment and their carers, who wish to remain in or be admitted to hospital but because 
of lack of capacity cannot do so informally. The stigma and loss of freedom associated with formal admissions can be appreciated by many who are incapable of giving consent according to the guidelines, and by their relatives.

For example, M. has severe learning disabilities, no spoken language and diabetes. She has lived for eight years in a group home, since resettlement from a large hospital where she lived for 20 years. For a week, M. has been eating little, staying at home and spending most nights awake. When well, she washes and dresses with prompting, helps with shopping and goes by taxi to a sheltered workshop. $M$. has had previous episodes of depression, her most recent admission being a year ago.

Usually $M$. responds to increased antidepressants and support from the community team. When a psychiatrist and community nurse (who had worked on the ward during her previous admission) visited her at home, she hugged them and cried. She was dehydrated, with multiple areas of broken skin on her arms and face, where she had been picking. She held the nurse's arm and waited while her carer packed. On arriving at the ward, she walked in still holding the nurse and carrying her own bag. She led him to the bedroom she had during her previous admission, and got into bed, only letting him go after her belongings were unpacked.

The wish not to 'section' a patient like this (both from carers and professionals) may lead to suboptimal care as people who would benefit from hospital treatment, or carers who would benefit from respite, may refuse an offered admission. The alternative (and even more draconian) option where a nearest relative refuses admission, is to seek a Court Order to remove their MHA rights.

The implications are different but no less disturbing for the patients unable to give consent but who do not fulfil the criteria for detention under the MHA. For example, people with dementia or learning disability and behavioural problems of a nature or severity which means that they cannot be looked after in local authority homes, appropriately and routinely have planned hospital respite admissions for the health of the carer. As the MHA allows admission for the protection of others - but not for their health, this group of patients can no longer legally be admitted to hospital. This is exemplified by $L$. who has dementia with Lewy bodies. His mobility is impaired by parkinsonism and he has visual hallucinations which are not disturbing to him but distress his wife who also washes, dresses and feeds him. She is exhausted and clinically depressed but is determined to look after $\mathrm{L}$. at home, if possible. She is enabled to do this by regular respite admissions, which must be in hospital because of L's bizarre behaviour in response to his hallucinations and his physical dependency. L. seems happy in hospital, where he thinks he is still at home.

These consequences for hospitalised patients are relatively clear cut. There may be equally devastating implications for a much larger group of people with mental health problems who lack decision-making capacity. If patients are unable to consent to admission and treatment, it may follow that they are unable to consent to community treatment, or to placement in residential or nursing homes. The Department of Health is obtaining advice on "what impact, if any, the judgement has on the management of other groups ... in other settings".

The direction taken by $L$. $v$. Bournewood is opposite to that of the recent consultation paper on mental incapacity: Who Decides? (Lord Chancellor's Department, 1997). Its theme is to ensure that people with limited capacity are able to make decisions within their capacity and only provided with an alternative decision-maker where this is necessary. The test proposed for determining capacity is whether a person can understand a simple explanation, using broad terms and with all practical steps taken to help them express their own decision. A new court framework is proposed for this approach, which would involve formalising existing informal dayto-day decision-making by carers. There would be a Council of Managers to take more important decisions; major issues would be referred to the courts. In addition, there is a proposal to create a broader (not purely financial) continuing power of attorney to empower the attorney to make proxy decisions on health care matters - an option not now avallable.

A similar approach to Who Decides?, together with appropriate changes to the law of consent, could be applied to assessing competence regarding psychiatric admission. Safeguards would certainly be required, and might include the formalisation of a second opinion procedure (involving a board of lay and medical representatives) if there is conflict between carers and psychiatrists. If the patient dissents, assessment under the MHA would be a reasonable option.

The current situation is untenable in terms both of unresolved resource demands and the imperative of providing a service that benefits users and carers. The solution which we suggest would require increased resources but not of the magnitude of the present state of the law. There is a compelling need for the case of $L$. $v$. Bournewood to be reviewed in the House of Lords; we understand that this is scheduled for June 1998, although it will be heard sooner if a vacancy arises. In addition, the Secretary of State has applied to the House of Lords to 'intervene' so that Counsel can attend on his behalf and clarify the wider implications of the 
case, overriding the focus on the specific legal issues raised by the $L$. $v$. Bournewood dispute. If the Court of Appeal's judgement is upheld, the Government will be required to act urgently to protect both the autonomy and the right to treatment of patients within a framework which allows the patient and the family to be heard.

\section{References}

Brown, M. (1997) Court of Appeal Judgement: L. $v$. Bournewood Community and Mental Health Trust. Letter to Chief Executives of NHS Trusts. London: Department of Health.

LORD ChanCELLOR'S DEPARTMENT (1997) Who Decides? Making Decisions on Behalf of Mentally Incapacitated Adults: A Consultation Paper. London: HMSO

SMITH, K., SHAH, A., WRIGHT, K., et al (1995) The prevalence and costs of psychiatric disorders and learning disabilities. British Journal of Psychiatry, 166, 9-18.

*Gill Livingston, Senior Lecturer in Psychiatry, Department of Psychiatry and Behavioural Sciences, UCL Medical School, Wolfson Building, 48 Riding House Street, London WIN 8AA; Sheila Hollins, Professor of the Psychiatry of Learning Disability, Department of Psychiatry of Learning Disability, St George's Medical School, London;
Cornelius Katona, Professor of Psychiatry of the Elderly, Department of Psychiatry and Behavioural Sciences, UCL Medical School, London; Helen Matthews, Senior Lecturer in the Psychiatry of Learning Disability, Department of Psychiatry of Learning Disability. St George's Hospital Medical School, London; Angela Hassiotis, Honorary Senior Lecturer in Learning Disability, Department of Psychiatry and Behavioural Sciences, UCL Medical School, London; Martin Blanchard, Senior Lecturer in Old Age Psychiatry, Royal Free Hospital Medical School, London; Nick Bouras, Senior Lecturer in Disability, Section of Disability, Division of Psychiatry and Psychology, UMDS, Guy's Hospital, London; Kim Davidson, Consultant in Psychiatry of Old Age, Kingston and District Community NHS Trust, Surrey: Janet Carrick, Regional Adviser in Psychiatry of Old Age and Consultant Psychiatrist, Mental Health Unit, Chase Farm Hospital, Enfield; Lindsay Gee, Solicitor, Capsticks Solicitors, London; Stella Wiltshire, Mental Health Manager, West Park Hospital, Surrey

*Correspondence

\section{Using the Mental Health Act
A Training Resource for Doctors
Prepared by the Royal College of Psychiatrists' Working Group}

This training pack is intended to support the development of better training for psychiatrists seeking approval under Section 12 of the Mental Health Act (1983) and to support the continuing education of psychiatrists and GPs. It comprises a 45 minute video, comprehensive written guidelines and lecture notes, together with overhead projector masters. It is intended as an aid (a) to those running training seminars within hospitals or trusts and others wishing to set up their own seminars, and (b) to individual practitioners who work in more isolated settings and who may wish to use distance learning. Published 1997, ISBN 190124209 9, 93 page text +18 unbound presentation masters, 1 PAL video cassette 45 min length. Video cassette and text held together in a white $P V C$ ring binder. Price $£ 45.00+$ VAT.

Available from Booksales, Publications Department, Royal College of Psychiatrists, 17 Belgrave Square, London SW1X 8PG (Tel. +44(0)171 235 2351, extension 146). The latest information on College publications is available on the INTERNET at: www.rcpsych.ac.uk 